\title{
The Role of Negative Politeness in Request: The Strategies that Non-Native Speakers Apply and Fail to Apply when Performing Request
}

Licenciada Romina Ariana Marazita

\begin{abstract}
As native speakers of a particular language, we are aware of its use as one of the most powerful tools for communication. The way we use language not only conveys a social aspect- that we are part of a speech community and share a discourse accent- but also shows the way we are: our personality, our ambitions, our power, our solidarity, etc. All these aspects, among many others, come into play in a conversation. The aim of this article is to analyze if non-native speakers are aware of the concept of negative politeness and how many different strategies they apply or fail to apply when performing requests. The strategies to be observed will be useful to identify the possible absence of pragmatic ability and the feasible teaching implications to improve pragmatic competence in non-native speakers; and, at the same time, reflect upon new approaches for the teaching of English as a foreign language.
\end{abstract}

Key words: Pragmatic competence, speech acts, politeness, negative politeness, face

\section{Introduction}

Whenever a speaker performs a request, he/she is not only uttering it as a question, statement or command, but performing an act which includes a certain number of conditions, characteristics and different kinds of effects: a speech act. The investigation of speech acts reflects the different abilities a speaker and hearer have to understand each other and make communication purposeful. But few speakers are aware of the skills required for valid speech acts. In fact, non-native speakers often find themselves in trouble when they realize they cannot adapt their speech to different situations they may come across. It has often been observed that students are not aware of the cultural milieu that surrounds speech acts and they do not make a difference between different types of contexts. What is more, there are usually breakdowns in communication produced by the lack of pragmatic ability. This kind of ability is included "under sociolinguistic competence, called 'rules of use'" (Rose \& Kasper, 2001). Of course, this forms part of the so-called Communicative Competence, described by Richards (1992) as "the ability not only to apply the grammatical rules of a language in order to form grammatically correct sentences but also to know when and where to use these sentences and to whom."

Referring to requests in particular, a native speaker of the language uses certain strategies in order to maintain norms and principles that form part of social interaction. As Bonn (2000) exposes: "Speaking in a polite manner involves being aware of the effect a particular illocutionary force has on one's addressee, and aggravating or mitigating this 
force by applying a suitable degree of modification."

One of these degrees of modification is Politeness, "the means employed to show awareness of another person's face" (Yule, 1996 p.6o). Every time a speaker performs a request, he/she is acquainted with the fact that conversations follow particular conventions and organizational principles. Strategies to perform requests vary according to context and along factors such as social power, role and status. And every speaker has the necessity to be appreciated by others and to feel that nobody is interfering with him (Renkema, 1999, p.27). But do non-native speakers know and apply those strategies when speaking? How aware are non-native speakers of the role of politeness and its different linguistic realizations in requests?

\section{Theoretical framework: the role of pragmatic competence}

In order to understand how non-native speakers behave and interact when confronted with different contexts and registers, it is important to establish which theories and disciplines provide a basis for our analysis. A definition of pragmatic competence is necessary to establish a parameter through which non-native speakers will be assessed.

Reyes (1994) exposes a very important factor that is commonly associated with pragmatic competence: "Communication springs from a powerful and previously made agreement between rational and efficient speakers who want to be understood. The agreement has to be constantly renovated, and this implies a constant conflict resolution" (p.57).

All these conflicts the speaker comes across are solved if this person counts on pragmatic ability to help him/her realize how to adapt and solve those clashes. As stated before, pragmatic ability is a very important skill that sometimes non-native speakers of English lack. This pragmatic ability forms part of Bachman's (1990) model of communicative ability (as cited in Rose \& Kasper, 2001, p.1), that includes pragmatic competence as one of the two principal components of language competence. Yet, organization competence is also considered. According to Bachman (ibid), sociolinguistic competence and illocutionary competence form part of pragmatic competence.

However, it is sometimes difficult for non-native speakers to develop this ability, since, for example, in the case of requests, strategies to perform them vary according to culture and communication patterns of each linguistic community. Non-native speakers sometimes underuse or overuse politeness strategies in the second language, without finding the right balance a native speaker would possess. In spite of the fact their grammatical competence is well developed, their pragmatic competence is left aside due to lack of pragmatic awareness towards the specific norms of a particular cultural and institutional context.

Rose \& Kasper (2001) conclude: "there is thus a strong indication that instructional intervention may be facilitative to, or even necessary for the acquisition of L2 pragmatic ability” (p.8).

\section{Requests}

When a speaker wants the hearer to commit to some future action, it is often more tactful to do so by means of a request, according to Leech \& Svartvik (1975) "to ask your hearer whether he is willing or able to do something" (p.147).

All the same, van Dijk (2000) proposed that speech acts have to be regulated by some conditions known as appropriateness (p.38).

As explained by Schiffrin (1994), Searle elaborated these conditions, commonly known as felicity conditions, for a request to be valid. To start with, the propositional content is the future action of the hearer. Second, the preparatory condition is that the Hearer is able to perform the action and that the speaker knows that the hearer is able to perform the action. Third, the sincerity condition is that the Speaker wants the hearer to perform the action. Finally, the essential condition is the attempt to get the hearer to do an action.

Some of the felicity conditions are common for both questions and requests. According to Schiffrin (1994) the differences between requests and questions is:“... what a speaker wants through a 
question (elicit information) is more specific than what a speaker wants through a request” (p.71)

Therefore, what he is pointing out is that questions are one specific type of requests. The point is that in order to classify any chunk of spoken discourse as a question, it is necessary to see the particular conditions that are required to obtain valid questions. According to Searle, (1969, p. 66) as cited in Schiffrin, (1994, p. 64) there are four types of rules for a question to be regarded as such:

1. preparatory rule: the speaker lacks knowledge of a particular state of affairs.

2. sincerity rule: the speaker wants to gain knowledge of a particular state of affairs.

3. essential rule: the attempt to elicit information from hearer

4. propositional content rule: any proposition

It has often been said that questions and requests have had a controversial relationship in Speech Act Theory. Schiffrin (1994) utters the following difference: "Directives differ from questions because the syntactic structure assumed to most directly manifest a directive is the imperative, whereas for a question is the interrogative one" (p.70).

However, differences overlap since this formfunction correlate is not absolute.

But what is the format of a request? As proposed by Blum-Kulka, et al (1989) in her book Cross-Cultural Pragmatic: Requests and Apologies, cited by Cohen (n.d.) online, the request segment in English includes three segments:

- Attention or Alerter: In general address terms to draw the hearer's attention

e.g. Maria,

- Head Act: the actual request e.g. Can you bring me the car keys?

- Supportive Move: before or after the head act, a phrase that indirectly modifies the illocutionary force of the request, by checking on availability, getting a precommitment from the hearer, a sweetener (expressing exaggerated admiration of the requestee's ability to fulfil the request), a disarmer (indicating knowledge of a potential offence), and cost minimizer (indicating contemplation of the imposition of the requestee involved)

e.g. You always know where I leave them!

The felicity conditions that are applied for requests and the different moves that are required for them to be regarded as valid gives us a clear idea of what a native speaker has to work out before uttering this speech act.

\section{The role of politeness and face}

Every time a speaker utters a request, he/she is requesting action from the hearer. But depending on their social roles and distance, (among other factors), the request will be different. The cause is that all human begins live in a society and lead social lives, so they try to preserve their (and the hearer's) identity and respect. This concept is known as Face, defined by Yule (1996 p. 60) as "the public self-image of a person"; in fact, "the emotional and social sense of self that everyone has and expects everyone else to recognize." The concept of Face forms part of a wider area, the area of Politeness, commonly described as "the means employed to show awareness of another person's face" (Yule, 1996, p. 60). Different types of awareness will lead to different types of requests. In general, for the purpose of succeeding, the speaker cooperates in order to maintain face. Why is that? Simply because as Kramsch, (1998, p. 26) points out: "Language users have not only learned to interpret signs and to act upon them, they have also learned to expect certain behaviours of others as well."

She also adds (ibid:46) that members need to feel respected and not intruded upon in their autonomy as well as to be reinforced in their view of themselves as respectful members of their culture.

According to Brown \& Levinson (1987 p. 58), all people possess positive and negative face, taking for granted that this human being has rationality, "the availability to our MP (model person) of a precisely definable mode of reasoning from ends to the means that will achieve those ends." In fact, positive face is defined as the necessity to be accepted by at least some others, whereas negative face is described as 
the desire to be independent, the desire that the action is unimpeded by others.

It is important to clarify that these particular concepts are also culture-specific, and that perhaps the Argentinian Society views face differently from the British or American Society. However, there are some areas of common ground between two people initiating a speech act set. As a result, an act that is oriented to the person's negative face will form part of Negative Politeness. Yet, if the act is concerned with this person's positive face, that is called Positive Politeness. (Yule, 1996, p. 62).

As Yule (ibid. p. 64) mentioned, in most English Speaking contexts a negative politeness strategy is used to perform a speech act. In negative politeness the speaker avoids a refusal, and the desire is to respect and not to interfere in the addressee's territory. Hudson (1996, p.114) takes a similar but not equal view of these kinds of politeness. He assumes that there is a solidarity-face and a power-face. Whereas solidarity-face refers to "the application and approval that others show for the kind of person we are, for our behaviour, for our values and so on", power-face is viewed as "a negative agreement not to interfere."

All these strategies are known by native speakers since they live in an English speaking community and have been experiencing various types of social roles and the use of politeness almost unconsciously, naturally. However, these strategies pose a challenge on non-native speakers, because in several cases, they are not aware of the social roles played in that community, and therefore, not conscious of the strategies that they might apply in a real situation.

According to Brown \& Levinson (1987 p.129), negative politeness is about minimizing a particular imposition of a face threatening act. Therefore, the speaker applies some strategies to achieve this:

The first choice for the speaker is to be direct and choose to be conventionally indirect.

e.g. Can you pass the sugar?

The second choice for the speaker is to avoid presumptions about the hearer and keeping ritual distance from the hearer. The speaker can opt for a hedge, defined by Brown \& Levinson (ibid, p.145) as a "particle, word or phrase that modifies the degree of membership of a predicate or noun phrase in a set " like in Pass the sugar, if you can.

A third possibility is to try not to coerce the hearer by being pessimistic (e.g. You couldn't possibly pass the sugar, could you?) by indicating that the weight of the act is not so big, leaving only distance and power as probable swaying factors (e.g. I just want to ask you if you could pass the sugar) or by giving deference. This is sometimes attained, in many languages, by the use of honorifics, titles or the use of plural pronouns to singular addresses.

The last choice for the speaker is to communicate his own want of not impinging on the hearer. This can be accomplished by the use of four different strategies:

Apologizing: I know you're very busy, but could you please pass the sugar?

I'm sorry to bother you, could you please pass the sugar?

Impersonalizing the act: It appears to me that the coffee needs more sugar.

Distancing from the hearer by stating the act as a general social rule and by nominalizing the expression so as to become more removed from the situation.

Offering partial compensation for the face threat: I'd be eternally grateful if you would pass the sugar.

A final word needs to be clarified about the role of negative politeness. All the strategies uttered by speakers are influenced by three factors: Power, Distance and Ranking of Imposition. Whereas social distance is a social dimension of similarity / difference within which speakers and Hearer stand for the purpose of an act; power is the degree to which the hearer can impose his own plans. The third factor, ranking of imposition, refers to the degree to which they are considered to interfere with an agent's wants of self-determination or support. 
As it can be observed, the role of politeness in the performance of speech acts, especially in requests, seems to be an important piece to complete the puzzle of successful communication. The following sections aims at presenting how non-native speakers of English deal with these factors.

\section{Methodology}

Subjects were seventy undergraduate students whose ages ranged from twenty two to fifty. There were sixty seven women and three men. This particular linguistic group was chosen because of their availability and advanced level of the target language; all of them are in the English Training Course, in $3^{\text {rd }}$ Year. This training course requires a First Certificate Level to begin the course of studies that lasts four years; and it is of a tertiary level. While the resultant sample tends to be fairly random, most of the subjects are currently teaching at schools or private institutes, a factor useful to take into consideration when evaluating their responses.

The Discourse Completion task included seven different situations in which a request is to be made by the subjects. Each situation included background information with all the necessary contextual clues to provide the context, such as setting, participant roles and degree of imposition. The situations chosen compile a number of ordinary and everyday contexts for a speaker of a certain language, ranging from a formal context where the speaker tries to change an important appointment to a person of higher authority; to a very informal context where the speaker requests something to his/her husband/ wife.

Their requests provided clues to analyze what strategies of negative politeness non native speakers used when making requests and to investigate whether non native speakers were aware of the use of politeness in the performance of speech acts.

The Discourse Completion Task was completed in class as class requirement. Subjects were given the tasks with the seven situations. Students were asked to read the seven situations carefully and write the request they found appropriate for each case. It is essential to clarify that students were not given a time limit to complete this task. (See Appendix 1 for discourse completion task)

\section{Findings: the use of negative politeness strategies}

In the first situation, the speaker, ideally, needs to avoid imposition on the hearer, because the hearer is a higher authority who kindly gave the speaker an appointment after a long time, and the speaker has to bother this person again in order to change the appointment. A native speaker would use a highlyordered strategy.

Apparently, there was a tendency to use the strategy "be pessimistic" over using a hedge or another strategy. $74 \%$ of the subjects thought that in this way they would avoid imposition on the hearer. According to the theory of politeness, this can be considered a good choice given the high degree of formality presented in this context. Another interesting factor to consider is that $14 \%$ chose to be direct and only $10 \%$ of the trainees chose to use a hedge, which would be the next strategy preferred.

The following situation is slightly different. Even though the hearer belongs to a higher authority, the speaker is supposed to have a more fluent relationship with him/her because they work in the same place. Nonetheless, the speaker may perhaps want to pay deference to the hearer by using a negative politeness strategy. Curiously enough, $61 \%$ of the speakers chose to be direct, instead of being pessimistic (25\%) or using a hedge (0\%). This choice can have two possible interpretations: Either the speaker felt comfortable speaking to the Head and did not see the need to pay deference to him/ her or the speaker was not aware of the register of the situation he/she was exposed to. One important element to take into account is that $14 \%$ of the speakers went for avoiding any kind of request. Instead, they opted for explaining the problem directly, without asking the hearer previously if they could speak about that.

The third situation places the speaker in an entirely different situation. The choice is slightly confusing. Almost the same amount of speakers chose to be direct and to be pessimistic. This means that the first group (the ones that chose to be pessimistic) made no attempt to distinguish this context from the one introduced in Situation1. It also implies that the second group (the ones that chose to be direct) established no distinction between the conversation with the Head of the school and with a close friend. 
Situation 4 posed a challenge on non-native speakers, since it was the reverse situation, if the one is compared with situation 3. In this case, the speaker has the authority, and can exert more power, because the books belong to him/her.

Non-native speakers failed to recognize the difference between asking for a favour and asking to return a book that belonged to them. Almost the same percentage of speakers in situation 3 and situation 4 went for the "be pessimistic" strategy; and what is more, $9 \%$ thought the "incurring debt" strategy was appropriate in this case. Yet, these subjects did not recognize or notice the context they had to deal with. In fact, there was not a need to incur debt because they were not asking a favour; on the contrary, they were the owners of the books lent.

Once more in Situation 5, the speaker takes control of the speech act. Of course, he has to ask the hearer to call again, which may require a degree of imposition, but at the same time, the imposition is minimized because the hearer is a friend.Although many speakers went for a direct strategy, almost the same number opted to be pessimistic, a strategy perhaps inappropriate for a moment of emergency or at least hurry. Once more, a significant percentage (41\%) failed to distinguish the kind of context presented.

The last two situations seem to confirm the pattern established while presenting the results of the discourse completion task. Situation 6 would form part of everyday life for a native speaker. Moreover, the speaker does not have to worry for imposing his/her wants on the hearer, since the hearer is his/ her husband/wife. Curiously enough, non-native speakers, more than $46 \%$, continued suggesting the strategy "be pessimistic" as a best choice for this request. The second preferred was "be direct" with the $38 \%$ of the participants. As a matter of fact, only $12 \%$ of the speakers applied a suitable strategy and most common in frequency of use: bald on record.

The same occurs in Situation 7, in this last case, the speaker has a higher authority on the hearer, and the degree of imposition is minimum. But if we observe the bar chart, the strategy "be pessimistic" was the preferred option, with the $49 \%$; followed by the $34 \%$ with the "be direct" strategy. Only $11 \%$ of the subjects understood the context as informal and one in which they had a higher authority and used a bald on record strategy.

This leads us to suppose that on the one hand, nonnative speakers are conscious of the concept of negative politeness, since in fact they managed to apply some of the strategies this theory proposes. On the other hand, they don't apparently succeed in applying them in the right situation. As it can be seen, many of the speakers surveyed did not make a difference between the different roles they had to play, the different positions and roles of the hearer, and the context presented.

\section{Discussion}

The analysis clearly supports the idea that non native speakers fail to apply a variety of negative politeness strategies, at least the ones a native speaker would use in those contexts. Moreover, when they applied a negative politeness strategy, they used it in the majority of contexts, without taking into account the differences between the different situations, powerface and solidarity-face.

Perhaps the most noteworthy observation to be made is that non-native speakers recognized the use of negative politeness strategies but mainly failed to apply them in an appropriate way. This is partly explained by the fact that sometimes grammatical proficiency does not draw a parallel with pragmatic proficiency. Kasper (2000) mentions the results of a study conducted by Bardovi-Harlig in 1999 which was grounded in a consistent finding in research on advanced learners' pragmatic ability: "high levels of grammatical competence do not guarantee concomitant high levels of pragmatic competence."

Nevertheless, it should be made clear that only 70 non-native speakers of English took part in the completion of the discourse completion task; and further research is needed to reach to the conclusion that non-native speakers fail to apply different concepts of politeness that they surely apply in their first language but not in the foreign language. Besides, further research can be useful to identify 
why these speakers also failed to apply positive transfer from their first language.

\section{Conclusion}

This article had the purpose of shedding light on a common issue observed and experienced by English language teachers: the lack of pragmatic ability observed in non-native speakers of an advanced level, demonstrated in this study by the use of requests. What is more, it also attempted at analyzing how non-native speakers failed to use different negative politeness strategies in dissimilar contexts, as well as pre-requests to avoid further imposition on the hearer.

The results showed a reality that cannot be ignored. On the contrary, the evidence that emerges from this study should be taken into consideration for revising teaching approaches that we, as teachers, commonly apply with our students. First of all, the lack of pragmatic ability observed can be the result of lack of authentic material used in the classroom, the most usual context for non-native speakers of English. The importance of the use of authentic material is that it provides the learner with real and spontaneous speech to observe, register, analyze and therefore apply when confronted with a real native-like situation.

Second, non native speakers should be advised to evaluate their own use of speech acts and monitor themselves at the moment of speaking. Teachers have a vital role in making them aware of the different contexts and registers they are presented with. This can be achieved by the use of role-plays and simulations in the class, in order to provide a real-like context for students to interact and take part. Kramsch (1993) suggests: "The teaching of foreign language must be made relevant to social life, where people need to communicate with each other in order to set the stage for possible mutual understanding."(p. 240)

Third, the fact that non native speakers fail to use a variety of negative politeness strategies suggests that probably, in many cases, they have not been exposed to them previously. As we all know, part of the exposure, if not the main exposure for many students in our country, stems from the course books they use in class. It is often heard that these course books do not provide students with a variety of politeness strategies, let alone advise these nonnative speakers of English on how these strategies should be used. In general, course books do not present a great range of linguistic structures to deal with formal and informal requests, or different downgraders or upgraders that go with the speaker's role. As a result, the foreign speaker is incapable of adapting to different contexts, even when their grammatical proficiency is high.

Last but most important, Pragmatics has been defined by Crystal (cited in Kasper, 1997) as the study of language from the point of view of users, taking into consideration their choices, the constraints and the effects their use of language has on other participants in the act of communication. This discipline attempts at finding justifications to all these aspects, aided by other disciplines, among them Sociolinguistics and Discourse Analysis. On discovering the reasons why native speakers act the way they act, they are not only developing the discipline itself but also aiding language teachers in their development as such. It is now the task and the responsibility for language teachers and language planning researchers to bridge the gap between these disciplines and the language classroom. Only then will non-native speakers feel at ease in the target language and culture; only then will educators have the possibility of helping their students develop the so-called Communicative Competence.

Licenciada Romina Ariana Marazita holds a B. A. in English awarded by Universidad de Belgrano in Argentina. She also holds a degree in English Teaching awarded by Profesorado Antonio Saenz; where she currently works as a teacher trainer. Romina also works at university in Universidad de Lanus. As regards her academic interests, her main area of interest is Sociolinguistics and Pragmatics, devoting most of her time to the research of pragmatic and sociolinguistic issues and their relations to the EFL classroom. Her main goal is to bridge the gap between these theories and the real classroom so as to help future teachers in their jobs.

\section{References}

Austin, J. L. (1962). How to do things with words. UK: OUP

Bonn, A. (2000). Acquiring 'different strokes': A longitudinal study of the development of L2 pragmatic 
competence. (Online). Retrieved June, 2005 from the World Wide Web: www.gfl-journal.com.

Brown, G.; Yule, G. (1983). Discourse analysis. UK: CUP.

Brown, P; Levinson, S. (1987). Politeness: Some universals in language usage. UK: CUP.

Cohen, A. (1996). Speech acts. In McKay, S. \& Hornberger, N. (eds) Sociolinguistics and language teaching . Cambridge: CUP.

Cohen, A. (n.d.). "Requests” (Online), University of Minnesota. Available from: http://www.carla.umn.edu/ speechacts/requests/index.html. (4th June, 2005).

Crystal, D. (1995). The Cambridge encyclopaedia of the English language. UK: CUP.

Hudson, R. (1996). Sociolinguistics. UK: Cambridge

Iñiguez Rueda, L. (2003). Análisis del discurso: Manual para las ciencias sociales. España: UOC.

Kasper, G. (1997). Can pragmatic competence be taught? (NetWork \#6) (Online). Honolulu: University of Hawaii, Second Language Teaching \& Curriculum Centre. Retrieved June, 2005 from the World Wide Web: http://www.nflrc.hawaii.edu/NetWorks/ NWo6/.

Kasper, G. (2000). Four perspectives on L2 pragmatic development' (Online) Retrieved from www.nflrc. hawaii.edu/networks/NW19.pdf May, 2009.
Kramsch, C. (1998). Oxford introductions to language study: Language and culture. UK: OUP.

Leech, G.; Svartvik, J. (1975). A communicative grammar of English. UK: Longman; pp. 147-153

Levinson, S. (1983). Pragmatics. UK: CUP.

Mey, J. (1993). Pragmatics: An introduction.UK: Blackwell

Renkema, J. (1999). Introducción a los estudios sobre el discurso. España: Gedisa.

Reyes, G. (1994). La pragmatica linguistica: El estudio del lUso del lenguaje. España: Montesinos.

Richards, J. et al. (1992). Dictionary of language teaching and applied linguistics. UK: Longman.

Rose, K and Kasper, G. (2001). Pragmatics in language teaching. UK: CUP.

Schiffrin, D. (1994). Approaches to discourse. USA: Blackwell

Searle, J. R. (1998). Mente, lenguaje y sociedad. España: Alianza Ensayo.

Tsui, A. (1992). A functional description of questions. In M. Coulthard, M. (ed.) Advances in spoken discourse analysis. London: Routledge, pp. 89-110.

Van Dijk, T. (2000). El Discurso Como Estructura y Proceso. España: Gedisa.

Yule, G. (1996) Oxford introductions to language study: Pragmatics. UK: OUP.

Kramsch, C. (1993). Context and culture in language teaching.

UK: OUP.

\section{APPENDIX I \\ DISCOURSE COMPLETIONTASK}

\section{Read the following situations and provide the most suitable request SITUATION 1}

You have an appointment with Professor D, who will kindly help you with an important topic for your final exam. However, due to a serious problem, it is impossible for you to go to this appointment. You know you had a hard time getting an appointment but you have decided to ask Professor D to change the appointment for the next week, if possible.

You say: 


\section{SITUATION 2}

This is your first year at School H. You are the $4^{\text {th }}$ form teacher and you find it difficult to control the group. After bearing lots of problems you decide to speak to the Head of the school immediately. The head is very busy because she has had two meetings in the afternoon and had to cope with behaviour problems. Yet, you insist on talking to her this afternoon,. You go to her office, where she is revising plans.

You say:

\section{SITUATION 3}

You are currently preparing a research paper about SLA. There is a very good book that could be essential for your research. A close friend of yours has used it before and you decide to ask her to lend you the book.

You say:

\section{SITUATION 4}

In order to study for a final exam, you need a book you had lent to your former colleague at school. In spite of the fact you do not know her very well (you only saw her three or four times at breaks), you were willing to lend her the book. Two months have gone by and she hasn't returned the book yet. You decide to ask her to return the book to you.

You say:

\section{SITUATION 5}

You are at home. A friend of yours phones you, and you answer the phone. The problem is that your baby is crying so you cannot talk at the moment. You decide to ask her / him to phone back later.

You say:

\section{SITUATION 6}

You are having dinner at home with your husband / wife. The salad hasn't been seasoned properly in your opinion. You decide to ask your husband / wife for some salt.

You say:

\section{SITUATION 7:}

As you work all day long, your son, who is 15 years old, helps you with the housework every day. It is nine in the morning, and before going to work you decide to ask him to clean up the kitchen today.

You say: 